\title{
The potential environmental role of fungi as a complication in COVID-19 infections
}

\begin{abstract}
COVID-19 is a severe acute respiratory syndrome caused by the SARS-CoV-2 virus and is currently at pandemic levels worldwide. This opinion paper considers what evidence there is for a fungal connection between the aetiology of illness and the role of climate and the local environment. The paper focuses mainly on China. Five themes are explored beginning with (1) social media reports of potential water damage at emergency healthcare buildings. This builds on the premise that damp indoor environments can promote elevated microbial growth from fungi, bacteria and yeasts causing occupant infection, or exposure or sensitivity reactions to spores/cellular debris/allergens or to a range of inflammatory mycotoxins. The second theme looks at (2) seasonal variations in key climate factors like temperature and humidity and are examined from the perspective of controlling virus transmission based on known epidemiological data trends. Thirdly, (3) large cities like Wuhan exploit the spongecity concept where water is controlled using engineering controls. Since excess water is a hallmark of mould growth in the built environment, the role of this particular planning effort is discussed. The fourth theme (4) discusses the emerging literature that severe and adverse COVID-19 complications may be caused by fungal co-infections. The evidence for this, builds on emerging clinical reports relating procalcitonin, interleukins and lung opacities with signs of severe illness and/or sepsis. The paper concludes with a review of several non-pharmacological, infection control interventions that may help in controlling the spread of this virus in other countries and regions.
\end{abstract}

Keywords: COVID-19, SARS-CoV-2, mould, water damaged buildings, building and property law, mould assessment, hygiene, building microbiology, influenza, humidity, social media, sponge city, procalcitonin, interleukins, public health, infection control, climate
Volume 8 Issue I - 2020

\author{
Cameron $L$ Jones ${ }^{1,2}$ \\ 'Biological Health Services, Australia \\ ${ }^{2}$ National Institute of Integrative Medicine, Australia
}

\begin{abstract}
Correspondence: Dr. Cameron L. Jones, Biological Health Services, Level I, 459 Toorak Rd, Toorak, Victoria, 3 | 42, Australia, Tel+61414998900, Email info@biologicalhealthservices.com.au
\end{abstract}

Received: March 09, 2020 | Published: April 20, 2020

\section{Introduction}

A recent Lancet editorial confirms that the COVID-19 infection is likely to spread to most if not all countries and that highly assertive infection control and response management measures are likely required elsewhere and outside China. ${ }^{1}$ Coronavirus disease and the influenza virus are similar in that both cause respiratory illness. Influenza is a global problem considered to affect between $5-10 \%$ of adults per annum. ${ }^{2}$ The global burden of influenza was estimated to approach 1 billion cases where 3-5 million were considered severe illness causing between 300,000-500,000 deaths per annum. ${ }^{3}$ In contrast to influenza, infection caused by the more recent SARSCoV-2 virus as at the final week of March 2020 stands at >1,215,000 cases across at least 209 countries or territories ${ }^{4,5}$ with an infection mortality rate ${ }^{6}$ between $3-4 \%$ compared with influenza at below $0.1 \%$. The epidemiological and clinical characteristics of COVID-19 are most likely to impact the elderly causing pneumonia and especially in those with pre-existing respiratory disorders or who may be immunocompromised. ${ }^{7,8}$ Further timely information is available from the WHO since the dynamics of this infection are evolving rapidly. ${ }^{9}$ The aim of this study is to discuss the potential environmental role of water, climate and fungi as a complication in COVID-19 infections. This comment covers five themes:

I. What western social media disclosures about defective building works associated with the quarantine or treatment effort in China have appeared? [Social media]
II. What do we know about climate conditions in Wuhan, which is the capital city of Hubei province and considered to be the origin of the virus outbreak in China? [Climate]

III. What is the potential connection between urban waterlogging and virus viability? [Water]

IV. If water is omnipresent, and in conjunction with elevated humidity, could this influence co-infections from other microorganisms like fungi? Are there any epidemiological findings that support this? [Co-infections from fungi?]

V. If there is some theoretical merit in using humidity for nonpharmacological nosocomial viral infection prevention and control, what would this mean for fungi within the context of the built environment? [Infection control strategies].

\section{Social media}

Using social media for event-based surveillance aims to flag public health events that may need rapid investigation as a new type of early warning system..$^{10}$ From January to late February 2020 there was considerable online social media activity on Twitter ${ }^{11,12}$ that focused first on the Chinese experience with the SARS-CoV-2 virus and COVID-19 infections, but which then expanded into discussions covering other world regions like South Korea, Iran and Italy. This online commentary provided a window into the emerging healthcare crisis in China and revealed to some extent how the government and healthcare workers were approaching this epidemic despite the far- 
ranging censorship of Chinese social media. Notable contributions to the dialogue surrounding sentiment and messaging in common social media platforms like Twitter and Facebook have focused on fighting panic with credible information to counter disinformation. ${ }^{13}$ For example, a recent paper reviewed how 'reliable' and 'questionable' information is distributed across different social media platforms like Gab, Reddit, YouTube, Instagram and Twitter. Twitter was found to be the most neutral, while Reddit and YouTube reduce or cut out unreliable sources. ${ }^{14}$ Interestingly, crisis and risk communication on social media is known to lack correlation with user verification or follower count while 'informative' messages were more likely to be shared..$^{15}$

To deal with COVID-19 case isolation, containment and hospitalization, the city of Wuhan built two field hospitals in ten days; even live streaming the construction process. ${ }^{16}$ Several social posts suggested that some of these rapidly constructed hospitals had been severely damaged by extreme weather events and that rainwater damage and leakage into the hospitals was occurring (Figure 1). The figures show several examples captioned to imply water leaking events at healthcare facilities used for the coronavirus. These videos were sourced from Twitter ${ }^{17}$ but were also reported in the mainstream media and on Reddit. ${ }^{18,19}$ It is notable that the China State Council Information Office quickly refuted these claims that the hospital had been damaged. ${ }^{20}$ These video reports if true are of immediate concern since they suggest that one or more of these newly constructed, temporary hospitals may have become water damaged. Unwanted water ingress into buildings can promote the growth of biological contaminants like bacteria, yeasts and moulds. When fungi grow at higher than normal levels indoors or colonize building elements, they have the ability to adversely impact the health and well-being of building occupants via the sick building syndrome. ${ }^{21}$ Most recently in the United States a mould infestation at the Seattle Children's Hospital was linked to the deaths of six children and has led to a class-action lawsuit. ${ }^{22}$ Indoor air quality mould tests at that hospital confirmed that water leaks, a dirty air handling system and overall filth all contributed to a build-up of unacceptable levels of Aspergillus fungi. ${ }^{23}$ Other hospitals in the United States have also experienced unwanted mould issues $;{ }^{24}$ while the research literature has reported on this topic and the legal implications for some time. ${ }^{25,26} \mathrm{In}$ Wuhan it is reported that there are 16 shelter hospitals and that some 'fever hospitals' are in sports arenas or exhibition center's due to the bed shortage at dedicated hospitals. The use of temporary shelters following natural disasters are known to affect people in a range of ways with obvious problems caused by crowding people at different stages of the infection cycle. This can lead to increased levels of person-to-person transmission or compromised quality of services along with the potential for possible shortages of basic food, water, and sanitation requirements.

More recently, a building used to quarantine infected persons in the south-eastern city of Quanzhou has collapsed..$^{27}$ The reason for the collapse is at this point unknown, however there is some recent history of dubious building practices involving substandard steel and concrete, which may turn out to be contributing factors. ${ }^{28,29}$ These examples suggest that some buildings used for emergency healthcare may not be fit for purpose and echoes the 'close enough' attitude of "Cha Bu Duo" by way of explanation, and potentially compounded by a lack of legislation in the construction industry. ${ }^{30}$ With regard to the videos purportedly showing water leakage into the emergency hospitals and since social media services are increasingly being used as digital disease outbreak early warning systems, it begs the question about how these rapid electronic communications are or should be incorporated into relevant decision making. ${ }^{31}$

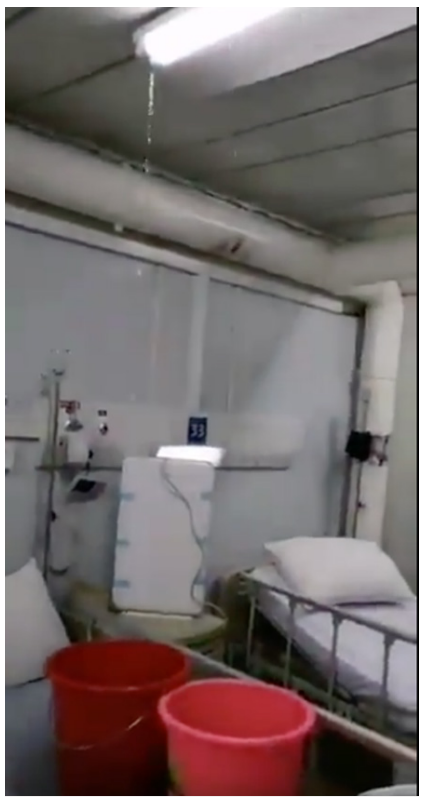

Figure IA Example \#I still image frame from a video post of water leak.

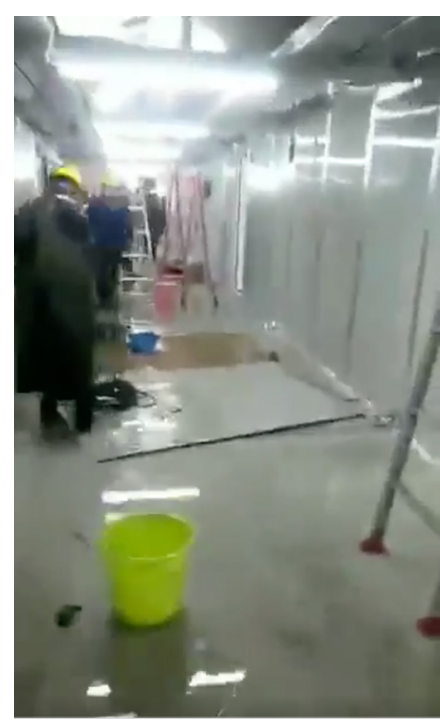

Figure IB Example \#2 still image frame from a video post of water leak.

\section{Climate}

Two publications of note report on dampness and mould in homes across China. ${ }^{32,33}$ One of the most common documented risk factors for adverse respiratory health is dampness in the built environment. The first paper $^{32}$ reports on common water damage indicators such as staining, windowpane condensation, mould odor, perception of humid air, or damp bedding as potential variables that could be correlated with mould-related exposure symptoms such as fatigue, headache, eye symptoms, and rhinitis or throat symptoms. The authors conclude that the warmer and more humid climate in southern China may contribute to an increased prevalence of dampness; however, health risks correlated with water damage and mould odor may in fact be higher in northern China due to those homes having less ventilation because of the cold climate. The second paper $^{33}$ found that mould 
growth in red brick buildings was a significant problem in winter and spring with a peak mould growth rate occurring in February. Average relative humidity in Wuhan, is already $73-77 \%$ year-round ${ }^{34}$ and at close to $80 \%$ most recently based on publicly available climate data for Wuhan, China would be cause for concern with respect to both mould growth and providing suitable humidity conditions that could favor the transmission of virus. ${ }^{35}$

Two concepts called relative humidity $(\mathrm{RH})$ and absolute humidity (AH) have been linked to influenza transmission rate but require at least some basic definitions. RH is the amount of water vapor in the air at a given temperature expressed as a percentage. $\mathrm{AH}$ is the total water content of the air measured in millibars. AH is higher at warm temperatures since the air can contain more water. Conversely, when it's cold the air can seem humid since $\mathrm{RH}$ is high but the amount of water in the air, or it's AH is low. Many studies report that both low and high RH favors transmission and survival of the influenza virus. The impact of climate and seasonal fluctuations is important, especially since knowledge about what factors might limit or promote viral disease transmission could be useful for treatment and prevention initiatives. ${ }^{36}$ Indeed, two papers have very recently discussed the role of humidity and SARS-CoV-2 transmission, but with opposite conclusions. The first looked at absolute humidity, AH over an 18-day period from January 23-February 10, 2020 and found that both dry and cold as well as high humidity areas had high levels of disease transmissibility measured using a proxy for the reproductive number as an estimate of infection. ${ }^{37}$ Despite clear differences in $\mathrm{AH}$ levels, the cumulative total number of cases did not appear weather related. In contrast, a more recent paper also looked at seasonal patterns and environmental factors on SARS-CoV-2 transmission $^{38}$ but over a similar time-frame (January-February, 2020), a much longer timeframe (November 2018 - March 2019 and included a predictive time-frame (March - April 2019). Here, relative humidity, RH, specific humidity, Q, AH and temperature, $\mathrm{T}$ were all examined. Their findings showed that through March 2020 there was a consistent community transmission pattern in a clustered band along the 30$50^{\circ} \mathrm{N}$ ' zone, capturing China, South Korea, Japan, Iran, Northern Italy, Northwestern Unites States, Spain and France and having both a low temperature range of $5-11^{\circ} \mathrm{C}$ and low $\mathrm{Q}$ and $\mathrm{AH}$. From this reference ${ }^{38}$ we see that significant adverse community outbreaks of COVID-19 occurred at low T and Q. Fundamental climatology trends between land surface Q, RH and T have been well documented across the seasons for the United States where RH does show an increase in winter and spring even though $\mathrm{Q}$ trends are more dominant than RH trends. Therefore, extrapolating from this reference, ${ }^{39}$ at higher $\mathrm{T}\left(20-30^{\circ} \mathrm{C}\right)$ and an $\mathrm{RH}$ between $40-60 \%$ avoids or minimizes the danger zone seen in SARS-CoV-2 community spread. From a risk assessment perspective, measurement of virus survival in the air and on surfaces cannot be underestimated. In turn, a recent publication showed airborne survival of at least $3 \mathrm{hr}$ and 2-3days on surfaces like stainless steel and plastic. ${ }^{40}$ Notably, comparative earlier research ${ }^{41}$ with surrogates for coronavirus (SARS-CoV-2) on surfaces; transmissible gastroenteritis virus (TGEV) and mouse hepatitis virus (MHV) showed much greater survival at low and high RH (20 and $80 \%$ ); which went down at a moderate RH of $50 \%$.

\section{Water}

The city of Wuhan has a well acknowledged flooding problem and in fact was once referred to as "the city of 100 lakes". ${ }^{42}$ It has a subtropical monsoon climate and experienced heavy rainfall leading to severe flooding in $2016 .{ }^{43}$ Increased urbanisation has led to many of these lakes being built over, while excess rain can quickly lead to flooding over impermeable roads and pavements when it can't drain into the ground. To address such problems, Wuhan is one of the pilot Cities that has applied eco-friendly, sustainable engineering solutions as a countermeasure to the impact of climate change and for flood management. Where existing pipe-based drainage is not sufficient to cope with all the water - in Wuhan, as in other countries like Germany and Japan and in cities like London, Birmingham and Edinburgh, China has applied something called the sponge city concept. ${ }^{44}$ This is an urban water management solution designed to deal with high rainfall and a corresponding lack of water in the dry part of the year. A sponge city manages water through six principles: infiltrate, detain, store, cleanse, use and drain. Examples of how this works include for example the use of pervious concrete, porous asphalt roads, rooftop gardens and watering plants with rainwater. The problem is that sponge cities although laudable in their approach to municipal water management may create localized build-up of high-water concentration that could then act to alter humidity patterns. Flooding in China is a serious issue and the literature suggests that over 32 million people were affected in 2016; while in Wuhan over $96 \%$ of inhabitants surveyed about urban floods had been affected either directly or indirectly with over $66 \%$ having experienced flooding at least once per year over the last decade..$^{45}$ The dominant personal impacts from urban flooding revealed: neighborhood flooding without damage to ones' own home at $49 \%$, flood water entered ones' home at $16 \%$, own workplace covered with water at $23 \%$ while $73 \%$ of persons reported transportation interference. An unintended consequence of the sponge city model is an increase in localized humidity where water is trapped. Unfortunately, water logging and flooding has been experienced in 10 of the first 16 sponge cities which suggest that municipal-scale civil engineering interventions for water management may not be as successful as intended. ${ }^{46}$ Interestingly, as measuring equipment improves, so does the scale at which problems can be resolved. For example, aerosol nanoparticles composed of fungal fragments are thought to play an important role in the climate system by affecting cloud formation which could then alter rainfall patterns as well as impacting on the levels of respirable allergens. ${ }^{47}$

\section{Co-infections - are fungi involved?}

The global burden from fungal diseases is increasing especially for those with malignancies, the immunosuppressed, neonates and the elderly, and involves opportunistic pathogens and endemic mycoses. ${ }^{48}$ An important article by Chen 49 examined the clinical characteristics of 99 cases of COVID-19 infection from Wuhan. Notably, antifungal treatment was initiated in $15 \%$ of treatments with coinfection from bacteria at $1 \%$ and with fungi at $4 \%$. Interestingly neutrophils were elevated in $38 \%$ of cases. However, an obvious question is what evidence is there for primary or secondary co-infections and COVID-19? There are in fact four emerging lines of evidence supporting this conjecture.

\section{Elevated biomarkers like procalcitonin}

The issue of secondary fungal infections and the potential need for antimicrobial prophylaxis in some COVID-19 patients showing extended disease and repeated fever was raised in a late February paper that discussed using elevated procalcitonin levels as an early warning biomarker for disease severity. ${ }^{50}$ The context for this is that approximately $15 \%$ of healthcare infections are caused by fungi, ${ }^{51}$ with Candida at $70-90 \%$ and those from Aspergillus at 10-20\%; while 
the lungs are the most frequent sites for patients with severe sepsis. ${ }^{52}$ Indeed, inflammation is a key feature of fungal and bacterial infections and endotoxin challenge leads to the production of proinflammatory cytokines that in turn stimulate procalcitonin release. ${ }^{53}$ Elevated levels of procalcitonin are also seen in Candidemia patients ${ }^{54}$ where this peptide precursor is involved with calcium regulation. The aim of a biomarker like procalcitonin is therefore to use it to trigger antimicrobial treatment initiation and duration, since the turnaround time for microbiological diagnosis is known to be long..$^{55} \mathrm{An}$ important review of the SARS-CoV-2 and COVID-19 literature revealed that the rate of patient admissions to the intensive care unit, ICU showed a 3-fold higher level of procalcitonin in serum compared to those who did not require ICU. ${ }^{56}$ The link between initial SARS-CoV-2 infection progressing towards adult respiratory distress syndrome and elevated procalcitonin levels was further discussed by the same authors in another publication. ${ }^{57}$ Here, increased procalcitonin values were associated with nearly a 5-fold higher risk of severe COVID-19 infection and could predict disease severity and complications. Although not a diagnostic panacea, biomarkers like procalcitonin show good diagnostic accuracy for discriminating between invasive fungal infections and bacterial or non-infectious conditions. ${ }^{58}$

\section{Lung abnormalities}

Thoracic imaging commonly uses chest radiography, CXR and computer tomography, $\mathrm{CT}$ to diagnose pneumonia..$^{59} \mathrm{~A}$ recent clinical study ${ }^{60}$ showed that a patient with severe symptoms from SARSCoV-2 pneumonia had a ground-glass halo on the CT. This pattern is seen most commonly in angioinvasive fungal infections and metastases. Another recent case series review of more COVID-19 patients confirmed that $57 \%$ had ground glass opacity, while $33 \%$ had rounded morphology ${ }^{61}$ It is the rounded morphology that is particularly concerning with respect to secondary infections, ${ }^{62}$ where the halo sign is commonly linked with aspergillosis and immunosuppression or in the immunocompetent, with cancer. ${ }^{63}$ Despite the fact the halo is nonspecific; its appearance is highly suggestive of early infection by a fungus. ${ }^{64}$ At present, the pathological driver - whether it is SARS$\mathrm{CoV}-2$, an underlying comorbidity or an opportunistic infection causing these CT scan observations remains unknown. ${ }^{65}$

\section{Other biomarkers like interleukins}

Inflammation has been closely related to disease severity of COVID-19 and cytokine mediators like interleukins, IL-6 and IL-8 are considered promising therapeutic targets, while elevated levels of other interleukins were also observed..$^{66}$ Other studies have found that IL-6 is a sensitive biomarker for acute pneumonias caused by either invasive aspergillosis or pneumocystis pneumonia, ${ }^{67}$ while IL-6 is up regulated in many cancers. ${ }^{68}$ Since one of the aims of this paper is to discuss other potential contributors to COVID-19 severity, it is interesting to look at what we know about IL-8 levels and the link between exposure to water-damaged buildings and increased adverse respiratory symptoms. Specifically, the paper by Akpinar-Elciet al. ${ }^{69}$ shows that IL-8 was elevated and statistically related to the number of symptoms and asthma in persons working in a building with a history of water damage and mould contamination. Earlier research ${ }^{70}$ showed that exposure to the fungus, Stachybotrys sp.from water damaged buildings induced the production of inflammatory markers like IL6. Interestingly, when other fungi were examined like Penicillium spinulosum, the effect of bacteria from the water damaged building was concluded to induce a stronger effect on IL-6 compared to fungi. ${ }^{71}$
However, similar research showed that exposure to Aspergillus versicolor caused not only acute lung injury and inflammation, but IL-6 levels were induced in a spore dose dependent manner. ${ }^{72}$ More recently, lab data showed that IL-6 levels could predict the severity of COVID-19 infection with over $93 \%$ accuracy. ${ }^{73}$

\section{Opportunistic fungal pathogens, other influenza and the built environment}

Aspergillus fungi are very common airborne fungi and are present in soils and decaying plant matter. If spores are inhaled, fungal hyphae can grow in the lungs leading to pulmonary aspergillosis. This has a global mortality rate of close to $45 \%$ at 3 months ${ }^{74}$ and is particularly serious for those with primary immune deficiencies. Invasive aspergillosis is normally considered a disease of immune compromised persons, although it is known to impact the non-immunocompromised host and is exacerbated by influenza infection..$^{75}$ Neutrophils are known to mount an immune response to Aspergillus fungi and to cause hyphal killing through reactive oxygen species. ${ }^{76}$ Research by Shevchenko et al. ${ }^{77}$ suggests that the number of neutrophils increases following Aspergillus fumigatus infection and is related to inflammation. There is substantial data also confirming that neutrophils are a core component of the viral response to infection. ${ }^{78}$ Worryingly, although a virus may be responsible for the influenza type initiating infection, mortality has long been suspected to be from a secondary infection like bacterial pneumonia or from fungal pneumonia caused from for example Aspergillus fumigatus. Various authors $^{79}$ have reported that severe influenza requiring intensive care admission is occurring even in the non-immunocompromised host together with invasive aspergillosis at levels up to nearly $20 \%$. Influenza associated aspergillosis has again been highlighted as recently as January 2020 with regard to risk factors for mortality seen in severe influenza patients. ${ }^{80}$

Another factor involves exposure to mould in the home environment, especially during quarantine or self-isolation and how this could pre-dispose persons to allergy and asthma-type effects prior to SARS-CoV-2 infection. For example, the paper by Salo et al. ${ }^{81}$ showed that exposure to indoor mould allergens were positively associated with asthma diagnosis and asthma-related symptoms; ${ }^{81}$ while the association between asthma and wheeze during influenza presents with some counterintuitive immunological benefit. ${ }^{82}$ Nevertheless, it's known that some persons with severe asthma are immunologically sensitized to fungi, and the home environment should not be underestimated as a trigger. Viral infections are also known risk factors for more serious invasive fungal co-infections. The high mortality rates seen may be due to steroids administered in intensive care ${ }^{83}$ which contrasts with the protective effect seen for asthmatics from steroids. This makes the epidemiology of SARSCoV-2 all the more important to carefully investigate, since the impact of co-infections from mould are already under-diagnosed or estimated $^{84}$ and could even be exacerbated by the comparatively high cost of CT scans. ${ }^{64}$ It is also worth mentioning that $\mathrm{PM}_{2.5}$ pollution also contains a significant biological component (both bacteria and fungi) and that bio aerosol dispersal of pathogenic fungi is highest in winter ${ }^{85} \mathrm{~A}$ survey of homes with children showed those with boys had higher numbers of viable fungi in the air space compared to homes with girls. ${ }^{86}$ Interestingly, it may be that continuous exposure to fungal fragments in damp air exerts an even more serious threat than intact spores, having higher pro-inflammatory potential. ${ }^{87}$ 
Emerging COVID-19 hotspots like Italy are also of concern since mould is known to be a serious problem in older buildings with one study showing a close correlation between water damage and mould estimated to affect at least $15 \%$ of homes. ${ }^{88}$ Another interesting study from Italy looked at the correlation between mould exposure and asthma and wheeze in children/adolescents relative to mould and dampness in the home. ${ }^{89}$ They report that visible mould in dwellings in Venice was $35 \%$ and that there was a lower presence of mould and dampness in the south versus the north and central Italy that was considered to be linked to the milder southern climate.

\section{Infection control strategies}

What are some of the non-pharmaceutical interventions that could be considered? Virus transmission occurs in 4 ways: direct contact (person-to-person), indirect contact (nosocomial and fomites) droplet (cough/sneeze) and airborne (aerosolized and dispersed by air currents); while mould exposure is fundamentally linked to dampness problems. ${ }^{90}$ A study by Taylor et al. ${ }^{91}$ reviewed many of the models and variables that impact on restoration and recovery efforts following flooding, with microbial growth critically linked to temperature and humidity, nutrient availability and heat transfer allowing materials to dry. ${ }^{91}$ The study by Paynter ${ }^{92}$ summarized several studies ${ }^{93}$ showing that a U-shaped function explains viral persistence and humidity, where maximum virus persistence is seen at low $\mathrm{RH}$, minimum persistence at $40-60 \% \mathrm{RH}$ and moderate persistence at higher RH (up to $80 \%$ ). This study was for influenza and respiratory syncytial virus (RSV) which are most frequently associated with respiratory tract infections, but these results could also extrapolate to other more severe human coronaviruses. It has been suggested by Metz \& Finn ${ }^{94}$ that artificially increasing humidity could reduce rates of influenza transmission, but that increasing AH could encourage fungal growth which would be deleterious. In practice, the use of home humidification equipment at a school over $4 \mathrm{hrs}$ increased indoor AH sufficient to decrease projected $1 \mathrm{hr}$ virus survival by $30 \%$ over winter. ${ }^{95}$ An earlier study ${ }^{96}$ showed that use of a portable humidifier in the bedroom decreased influenza survival by $15.5-31.6 \%$. In related work, ${ }^{97}$ it is known that viral decay increases linearly with salt concentration and that when RH reduces from $85 \%$ to $50 \%$ that viability depends on the droplet composition. Comparative research showed similar trends. ${ }^{98,99}$ In practice, one could easily use a combination of a dehumidifier and a humidifier as required to manually control the personal environment in the home or office in an effort to minimize virus viability by following the viability dip in the U-shaped function and setting indoor RH to $\sim 50 \%$.

The observation about moisture and viral persistence has then been exploited to develop a prototype virus deactivation system using sodium chloride salt impregnated into surgical masks; ${ }^{100}$ while the basic principle of sea salt impregnated air filters has been developed for deactivating bacteria. ${ }^{101}$ The reason this works is that the viability of an airborne virus is mediated by the salt concentration within droplets and similarly, sodium chloride is a well-known antifungal agent that changes osmoregulation in the cell. Hence salts cause virus inactivation by crystal formation, or cell dysregulation with respect to fungi; both of which may be aspects of aerosol transmission of infection. Disaster risk reduction must include basic safety measures that minimize the potential for water intrusion and if such events do occur then written plans for dealing with restoring a water damaged building to a pre-event condition 1 (normal mould ecology) state should have been formulated or acted on. Vigilance against building defects or dilapidation that could cause unwanted water ingress or accumulation and timely attention to repairs must also be addressed.
Remediation must also reduce the potential of condition 2 (settled spores) or condition 3 (actual growth) of mould known to cause or exacerbate either one or more of local airborne, cross contamination dispersion or surface contamination events. ${ }^{102}$ This becomes increasingly important when emergency accommodation was reviewed in the context of sick building syndrome where it was found that intrinsic building characteristics of construction including the use of synthetic materials, potentially poor ventilation and insulation were the most common variables that influenced the onset of upper and lower airway symptoms and impacts on general and ocular health. ${ }^{103}$ This is also even more important as social distancing and work-fromhome and home-quarantine measures are being implemented, ${ }^{104}$ especially considering the relationship between indoor air quality and public health.

With an increasing focus on infection control and efforts to reduce community transmission of SARS-CoV-2, the role of environmental cleaning cannot be underestimated. Very recently it was shown that nosocomial outbreaks from respiratory droplets and fecal shedding cause environmental contamination of for example bed rails, light switches, window glass and air outlet fans. ${ }^{105}$ In conclusion, the role of viral, fungal and bacterial biomes are important new ways of looking at how communities of microbes influence human health through transmission and exposure within the home and other built and urban environments. With regard to COVID-19, we still have much to learn.

\section{Acknowledgments}

The author thanks the anonymous reviewers for valuable feedback on earlier drafts of this manuscript.

\section{Conflicts of interest}

The author declares that there is no conflict of interest.

\section{References}

1. COVID-19: too little, too late? The Lancet. 2020;395(10226):755.

2. World Health Organization. Influenza. 2020.

3. Clayville LR. Influenza update: a review of currently available vaccines. P T. 2011;36(10):659-684.

4. WHO Coronavirus (COVID-19) Situation. 2020.

5. COVID-19 Coronavirus Pandemic. Worldometer. 2020.

6. Coronavirus disease 2019 (COVID-19) Situation Report - 46. 2020.

7. Wang C, Liu L, Hao X, et al. Evolving Epidemiology and Impact of Nonpharmaceutical Interventions on the Outbreak of Coronavirus Disease 2019 in Wuhan, China. medRxiv, 2020.

8. Expert Group on Prevention and Control of New Coronavirus Pneumonia of Chinese Preventive Medicine Association. New Understanding of Epidemiological Characteristics of New Coronavirus Pneumonia. Chinese Journal of Epidemiology. 2020:41.

9. WHO. Coronavirus disease (COVID-19) outbreak. 2020.

10. World Health Organization. Early detection, assessment and response to acute public health events. 2020.

11. Jahanbin $\mathrm{K}$, Rahmanian $\mathrm{V}$. Using twitter and web news mining to predict COVID-19 outbreak. Asian Pac J Trop Med. 2020.

12. Chen E, Lerman K, Ferrara E. COVID-19: The First Public Coronavirus Twitter Dataset. arXiv.org. 2020. 
13. Zarocostas J. How to fight an infodemic. The Lancet. 2020;395:676.

14. Cinelli M, Quattrociocchi W, Galeazzi A et al. The COVID-19 Social Media Infodemic. arXiv.org. 2020.

15. Lachlan $\mathrm{K}, \mathrm{Xu} \mathrm{Z}$, Hutter E, et al. A Little Goes a Long Way: Serial Transmission of Twitter Content Associated with Hurricane Irma and Implications for Crisis Communication. Journal of Strategic Innovation and Sustainability. 2019;14(1).

16. Construction of 2 new Wuhan hospitals being live streamed. 2020.

17. If you have or know of any photos or video showing water damage at any of the new hospitals in Wuhan please contact me. 2020.

18. News T. Video shows interior of new Wuhan hospital badly leaking water. 2020 .

19. China's surreal virus hospital claims. 2020.

20. Wuhan authorities refute claims of hospital damage- China.org.cn. 2020

21. Singh J, Yu C, Jeong Tai Kim. Building Pathology, Investigation of Sick Buildings-Toxic Moulds. Indoor and Built Environment. 2010;19:4047

22. CLASS ACTION COMPLAINT, Plaintiff v. SEATTLE CHILDREN'S HOSPITAL. 2020.

23. Infection Control Today. Aspergillus Said to Have Claimed Another Baby's Life at Seattle Children's Hospital. 2020.

24. Masson G. 5 hospitals facing mold issues this year: Numerous hospitals have detected molds in their facilities over the past year, capturing the attention of readers. 2020.

25. Caggiano G, Napoli C, Coretti C, et al. Mold contamination in a controlled hospital environment: a 3-year surveillance in southern Italy. BMC Infectious Diseases. 2014

26. Lee T. Mold remediation in a hospital. Toxicology and Industrial Health 2009;25(9-10):723-730.

27. RT International. Chinese hotel used as Covid-19 quarantine site COLLAPSES, trapping dozens under rubble (VIDEOS). 2020.

28. Headlines L, Service. Substandard building practices blamed for deaths in China. India Today; 2020.

29. Steadman I. Poor-Quality Chinese Concrete Could Lead to Skyscraper Collapses. 2020 .

30. Ting M. Building on Shaky Ground: Quality and Safety in China's Construction Industry in the Wake of the Wenchuan and Yushu Earthquakes. Construction Economics and Building. 2010;10:62-75.

31. Yousefinaghani S, Dara R, Poljak Z, et al. The Assessment of Twitter's Potential for Outbreak Detection Avian Influenza Case Study. Sci Rep. 2019;9(1).

32. Zhang X, Norbäck D, Fan Q, et al. Dampness and mold in homes across China: Associations with rhinitis, ocular, throat and dermal symptoms, headache and fatigue among adults. Indoor Air. 2018;29(1):30-42.

33. He Y, Chen G, Luo Q, et al. Evaluation of Mould Growth on Wall Surface in South China. Procedia Engineering. 2017;205:4135-4141.

34. Zhang X, Norbäck D, Fan Q, et al. Dampness and mold in homes across China: Associations with rhinitis, ocular, throat and dermal symptoms, headache and fatigue among adults. Indoor Air. 2018;29(1):30-42.

35. Wolkoff P. Indoor air humidity, air quality, and health - An overview International Journal of Hygiene and Environmental Health. 2018;221(3):376-390.

36. Cohen J. Why do dozens of diseases wax and wane with the seasons - and will COVID-19? Science. |AAAS. 2020.
37. Luo W, Majumder M, Liu D, et al. The role of absolute humidity on transmission rates of the COVID-19 outbreak. medRxiv. 2020.

38. Sajadi Mohammad M, Habibzadeh, Parham, Vintzileos Augustin, et al. Temperature, Humidity and Latitude Analysis to Predict Potential Spread and Seasonality for COVID-19. 2020.

39. Gaffen D, Ross R. Climatology and Trends of U.S. Surface Humidity and Temperature. Journal of Climate. 1999;12(3).

40. Van Doremalen N, Bushmaker T, Morris D, et al. Aerosol and Surface Stability of SARS-CoV-2 as Compared with SARS-CoV-1. New England Journal of Medicine. 2020.

41. Casanova L, Jeon S, Rutala W, et al. Effects of Air Temperature and Relative Humidity on Coronavirus Survival on Surfaces. Appl Environ Microbiol. 2010;76(9):2712-2717.

42. The Guardian. Inside China's leading 'sponge city': Wuhan's war with water. 2020.

43. Jiang Y, Zevenbergen C, Ma Y. Urban pluvial flooding and stormwater management: A contemporary review of China's challenges and "sponge cities” strategy. Environmental Science \& Policy. 2018;80:132-143.

44. Chan F, Griffiths J, Higgitt D, et al. "Sponge City" in China-A breakthrough of planning and flood risk management in the urban context. Land Use Policy. 2018;76:772-778.

45. Zhang S, Zevenbergen C, Rabé P, et al. The Influences of Sponge City on Property Values in Wuhan, China. Water. 2018;10(6):766.

46. Griffiths J, Chan F, Shao M, et al. Interpretation and application of Sponge City guidelines in China. Philosophical Transactions of the Royal Society A: Mathematical, Physical and Engineering Sciences. 2020;378(2168):20190222.

47. Lawler M, Draper D, Smith J. Atmospheric fungal nanoparticle bursts Science Advances. 2020;6(3): p.eaax9051

48. Lee P, Lau Y. Cellular and Molecular Defects Underlying Invasive Fungal Infections-Revelations from Endemic Mycoses. Frontiers in Immunology. 2017:8.

49. Chen N, Zhou M, Dong X, et al. Epidemiological and clinical characteristics of 99 cases of 2019 novel coronavirus pneumonia in Wuhan, China: a descriptive study. The Lancet. 2020;395(10223):507513.

50. Xu K, Cai H, Shen Y, et al. [Management of Corona Virus disease-19 (COVID-19): The Zhejiang Experience]. Zhejiang Da Xue Xue Bao Yi Xue Ban. 2020;49(1)

51. Delaloye J, Calandra T. Invasive candidiasis as a cause of sepsis in the critically ill patient. Virulence. 2013;5(1):161-169.

52. Lippi G. Sepsis biomarkers: past, present and future. Clinical Chemistry and Laboratory Medicine (CCLM). 2019;57(9):1281-1283.

53. Leli C, Ferranti M, Moretti A, et al. Procalcitonin Levels in GramPositive, Gram-Negative, and Fungal Bloodstream Infections. Dis Markers. 2015;2015:1-8.

54. Hakamifard A, Yazdani M, Khorvash F. Serum procalcitonin levels of patients with candidemia hospitalized in Intensive Care Units. Journal of Medical Sciences. 2018;38(3):113.

55. Raineri S, Cortegiani A, Vitale F, et al. Procalcitonin for the diagnosis of invasive candidiasis: what is the evidence? J Intensive Care. 2017;5(1)

56. Lippi G, Plebani M. Laboratory abnormalities in patients with COVID-2019 infection. Clinical Chemistry and Laboratory Medicine (CCLM). 2020

57. Lippi G, Plebani M. Procalcitonin in patients with severe coronavirus disease 2019 (COVID-19): A meta-analysis. Clinica Chimica Acta. 2020;505:190-191. 
58. Yu-Hong Dou, Ji-Kun Du, He-Lu Liu, et al. The role of procalcitonin in the identification of invasive fungal infection - a systemic review and meta-analysis. Diagnostic Microbiology and Infectious Disease. 2013:464-469.

59. Hayden GE, Wrenn KW. Chest Radiograph vs. Computed Tomography Scan in the Evaluation for Pneumonia. The Journal of Emergency Medicine. 2009;36(3):266-270.

60. Li X, Zeng X, Liu B, et al. COVID-19 Infection Presenting with CT Halo Sign. Radiology: Cardiothoracic Imaging. 2020;2(1):e200026.

61. Chung M, Bernheim A, Mei X, et al. CT Imaging Features of 2019 Novel Coronavirus (2019-nCoV). Radiology. 2020;295(1):202-207.

62. Kay F, Abbara S. The Many Faces of COVID-19: Spectrum of Imaging Manifestations. Radiology: Cardiothoracic Imaging. 2020;2(1):e200037.

63. Alves GR, Marchiori E, Irion K, et al. The halo sign: HRCT findings in 85 patients. J Bras Pneumol. 2016;42(6):435-439.

64. Georgiadou SP, Sipsas NV, Marom EM, et al. The diagnostic value of halo and reversed halo signs for invasive mold infections in compromised hosts. Clin Infect Dis. 2011;52(9):1144-1155.

65. Ye Z, Zhang Y, Wang Y, et al. Chest CT manifestations of new coronavirus disease 2019 (COVID-19): a pictorial review. Eur Radiol. 2020.

66. Gong J, Dong H, Xia S, et al. Correlation Analysis Between Disease Severity and Inflammation-related Parameters in Patients with COVID-19 Pneumonia. medRxiv. 2020.

67. Shen HP, Tang YM, Song H, et al. Efficiency of interleukin 6 and interferon gamma in the differentiation of invasive pulmonary aspergillosis and pneumocystis pneumonia in pediatric oncology patients. Int J Infect Dis. 2016;48:73-77.

68. Taniguchi K, Karin M. IL-6 and related cytokines as the critical lynchpins between inflammation and cancer. Semin Immunol. 2014;26(1):54-74.

69. Akpinar-Elci M, Siegel PD, Cox-Ganser JM, et al. Respiratory inflammatory responses among occupants of a water-damaged office building. Indoor Air. 2008;18(2):125-130.

70. Nielsen KF, Huttunen K, Hyvärinen A, et al. Metabolite profiles of Stachybotrys isolates from water-damaged buildings and their induction of inflammatory mediators and cytotoxicity in macrophages. Mycopathologia. 2002;154(4):201-205.

71. Huttunen K, Hyvärinen A, Nevalainen A, et al. Production of proinflammatory mediators by indoor air bacteria and fungal spores in mouse and human cell lines. Environ Health Perspect. 2003;111(1):8592.

72. Jussila J, Komulainen H, Kosma VM, et al. Spores of Aspergillus versicolor isolated from indoor air of a moisture-damaged building provoke acute inflammation in mouse lungs. Inhal Toxicol. 2002;14(12):1261-1277.

73. Gao Y, Li T, Han M, et al. Diagnostic Utility of Clinical Laboratory Data Determinations for Patients with the Severe COVID-19. J Med Virol 2020 .

74. Lanternier F, Cypowyj S, Picard C, et al. Primary immunodeficiencies underlying fungal infections. Curr Opin Pediatr. 2013;25(6):736-747.

75. Schauwvlieghe A, Rijnders B, Philips N et al. Invasive aspergillosis in patients admitted to the intensive care unit with severe influenza: a retrospective cohort study. The Lancet Respiratory Medicine. 2018;6(10):782-792.

76. Gazendam R, van Hamme J, Tool A, et al. Human Neutrophils Use Different Mechanisms To Kill Aspergillus fumigatus Conidia and Hyphae: Evidence from Phagocyte Defects. The Journal of Immunology. 2015;196(3):1272-1283.
77. Shevchenko MA, Bogorodskiy AO, Troyanova NI, et al. Aspergillus fumigatus Infection-Induced Neutrophil Recruitment and Location in the Conducting Airway of Immunocompetent, Neutropenic, and Immunosuppressed Mice. Journal of Immunology Research. 2018:1-12.

78. Camp J, Jonsson C. A Role for Neutrophils in Viral Respiratory Disease. Frontiers in Immunology. 2017.

79. Lamoth F, Calandra T. Let's add invasive aspergillosis to the list of influenza complications. The Lancet Respiratory Medicine. 2018;6(10):733-735.

80. Verweij P, Brüggemann R, Wauters J, et al. Influenza Coinfection: $\mathrm{Be}(\mathrm{a})$ ware of Invasive Aspergillosis. Clinical Infectious Diseases. 2019;70(2):349-350.

81. Salo PM, Xia J, Johnson CA, et al. Indoor allergens, asthma, and asthmarelated symptoms among adolescents in Wuhan, China. Annals of Epidemiology. 2004;14(8):543-550.

82. Veerapandian R, Snyder J, Samarasinghe A. Influenza in Asthmatics: For Better or for Worse? Frontiers in Immunology. 2018;9:1843.

83. Huang L, Zhang N, Huang X, et al. Invasive pulmonary aspergillosis in patients with influenza infection: A retrospective study and review of the literature. The Clinical Respiratory Journal. 2019;13(4):202-211.

84. Naish J. How the flu could leave you at the mercy of killer fungus. 2019.

85. Du P, Du R, Ren W, et al. Variations of bacteria and fungi in PM2.5 in Beijing, China. Atmospheric Environment. 2018;172:55-64.

86. Fang Z, Tang Q, Gong C, et al. Profile and distribution characteristics of culturable airborne fungi in residential homes with children in Beijing, China. Indoor and Built Environment. 2015;26(9):1232-1242.

87. Holme JA, Øya E, Afanou AKJ, et al. Characterization and proinflammatory potential of indoor mold particles. Indoor Air. 2020.

88. Norbäck D, Zock JP, Plana E, et al. Building dampness and mold in European homes in relation to climate, building characteristics and socioeconomic status: The European Community Respiratory Health Survey ECRHS II. Indoor Air. 2017;27(5):921-932.

89. Simoni M. Mould/dampness exposure at home is associated with respiratory disorders in Italian children and adolescents: the SIDRIA-2 Study. Occupational and Environmental Medicine. 2005;62(9):616-622.

90. World Health Organization. WHO guidelines for indoor air quality: dampness and mould. 2009.

91. Taylor J, Lai KM, Davies M, et al. Flood management: Prediction of microbial contamination in large-scale floods in urban environments. Environment International. 2011;37(5):1019-1029.

92. Paynter S. Humidity and respiratory virus transmission in tropical and temperate settings. Epidemiology and Infection. 2014;143(6):1110-1118.

93. Noti J, Blachere F, McMillen C, et al. High Humidity Leads to Loss of Infectious Influenza Virus from Simulated Coughs. PLoS ONE. 2013;8(2):e57485.

94. Metz JA, Finn A. Influenza and humidity - Why a bit more damp may be good for you! Journal of Infection. 2015;71:S54-S58.

95. Koep TH, Enders FT, Pierret C, et al. Predictors of indoor absolute humidity and estimated effects on influenza virus survival in grade schools. BMC Infectious Diseases. 2013;13(1).

96. Myatt TA, Kaufman MH, Allen JG, et al. Modeling the airborne survival of influenza virus in a residential setting: the impacts of home humidification. Environmental Health. 2010;9(1).

97. Yang W, Elankumaran S, Marr L. Relationship between Humidity and Influenza A Viability in Droplets and Implications for Influenza's Seasonality. PLOS ONE. 2012;7(10):e46789. 
98. Reiman J, Das B, Sindberg G, et al. Humidity as a non-pharmaceutical intervention for influenza A. PLoS ONE. 2018;13(9):e0204337.

99. Nikitin N, Petrova E, Trifonova E, et al. Influenza Virus Aerosols in the Air and Their Infectiousness. Adv Virol. 2014;2014:1-6.

100. Quan F, Rubino I, Lee S, et al. Universal and reusable virus deactivation system for respiratory protection. Scientific Reports. 2017:7(1).

101. Jeong SB, Heo KJ, Lee BU, et al. Antimicrobial Air Filters Using Natural Sea Salt Particles for Deactivating Airborne Bacterial Particles. International Journal of Environmental Research and Public Health. 2019;17(1):190.

102. iicrc.org. ANSI/IICRC S520 Standard and IICRC R520 Reference Guide for Professional Mold Remediation. 2020.
103. Muzi G, Accattoli M, Dell'omo M, et al. Sick Building Syndrome like Symptoms in Emergency Prefabricated Accommodation. International Journal of Immunopathology and Pharmacology. 2004;4(2):103-108.

104. Koo J, Cook A, Park M et al. Interventions to mitigate early spread of SARS-CoV-2 in Singapore: a modelling study. The Lancet Infectious Diseases. 2020

105. Ong S, Tan Y, Chia P, et al. Air, Surface Environmental, and Personal Protective Equipment Contamination by Severe Acute Respiratory Syndrome Coronavirus 2 (SARS-CoV-2) From a Symptomatic Patient. JAMA. 2020 